\title{
Epidemiology of Idiopathic Cardiomyopathy in Qatar during 1996-2003
}

\author{
Ayman A. El-Menyar ${ }^{a}$ Abdulbari Bener ${ }^{b} \quad$ Mohammed T. Numan ${ }^{a}$ \\ Salwa Morcos ${ }^{a}$ Ruba Y. Taha ${ }^{\mathrm{C}}$ Jassim Al-Suwaidi ${ }^{\mathrm{a}}$ \\ Departments of ${ }^{a}$ Cardiology and Cardiovascular Surgery, ${ }^{b}$ Medical Statistics and Epidemiology and \\ ${ }^{c}$ Medicine, Hamad General Hospital, Doha, Qatar
}

\section{Key Words}

Epidemiology $\cdot$ Consanguinity $\cdot$ Cardiomyopathy $\cdot$ Qatar

\begin{abstract}
Objectives: To report the rates of cardiomyopathies in the population below 50 years of age in Qatar. Subjects and Methods: We conducted a retrospective review of clinical data on patients with cardiomyopathy who were hospitalized in Hamad General Hospital, Doha. Data were collected from medical records during the 19962002 period and prospectively from the patients who were hospitalized during the year 2003. All cardiomyopathy patients below 50 years of age who were citizens or permanent residents in Qatar were included in this study. Results: During the study period, a total of 132 cases were recorded with idiopathic cardiomyopathies. Among these, $67.4 \%$ were males and $32.6 \%$ females; Qatari $31.8 \%$, non-Qatari $68.2 \%$. The consanguinity rate was high among Qatari patients. In the first 7-year study period, 1996-2002, the incidence rate of all types of cardiomyopathies was $2.5 / 100,000$ population per year (95\% Cl: 1.4-3.5). It increased to $5.2 / 100,000$
\end{abstract}

population during the year 2003 (95\% Cl: 3.6-6.7). Dilated cardiomyopathy was most prevalent $(75.8 \%)$ in all age groups, and the incidence increased remarkably with age. Lower prevalence of hypertrophic cardiomyopathy $(13.6 \%)$ and left ventricle noncompaction cardiomyopathy $(6.1 \%)$ was found. In children below 15 years of age, the incidence rate for all types of cardiomyopathies was $2.7 / 100,000$ population. The overall mortality rate was 5.3\%. Conclusion: Most cases of cardiomyopathy were identified at an early age: below 15 years and above 35 years of age. Introducing preventive and early diagnosis programs may have an impact on reducing the mortality and morbidity from idiopathic cardiomyopathy.

Copyright (c) 2006 S. Karger AG, Basel

\section{Introduction}

Congestive heart failure (CHF) has been termed the 'new epidemic of cardiovascular disease' in the new millennium. In spite of the importance of this disease worldwide, little information is available about the epidemiology of CHF in the developing world $[1,2]$. There are no

\section{KARGER}

Fax +4161306 1234 E-Mail karger@karger.ch www.karger.com 
population-based studies, examining the prevalence and causes of CHF in young patients in Qatar. This information is needed in order to develop strategic planning for prevention and treatment of this rising epidemic. The prevalence of the various types of cardiomyopathies may be different from those reported elsewhere and this may warrant specific strategic planning [3, 4]. Furthermore, the Qatari population, like other Arabian Gulf countries, has consanguineous family structure that is different from most of the world population.

In Qatar, the consanguinity rate is very high. Therefore, the population is in principle genetically homogenous [5]. This will serve as an ideal population for studying the genetics of cardiomyopathies with respect to the nature of the genetic polymorphism that can influence the power and interpretation of epidemiological data when dealing with more out-bred and heterogeneous populations. This study examined the rates of cardiomyopathies in the population below 50 years of age in Qatar, in the 1996-2003 period.

\section{Subjects and Methods}

We analyzed the data with respect to all patients below 50 years of age who were hospitalized with idiopathic cardiomyopathy during the 1996-2003 period. This study was based at Hamad General Hospital, Doha, which is the main tertiary care center in the country. Hence it was an ideal site for population-based studies. All patients with various types of cardiomyopathy were treated at this hospital. In the present study, the subjects were recruited from the Department Cardiology. The data were collected retrospectively from the medical records of the patients during the 1996-2002 period when they visited outpatient clinics for follow-up, and for the year 2003 it were prospective data from the clinical records at the time of patient's hospital discharge. Cases of cardiomyopathy were classified according to World Health Organization/International Society and Federation of Cardiology task force on Cardiomyopathies $[6,7]$. The inclusion criteria were subjects aged below 50 years and all nationalities in Qatar presenting with any type of cardiomyopathy. Those suffering from end-stage rheumatic valvular heart disease and $\mathrm{CHF}$ complicating acute myocardial infarction were excluded.

The studied subjects had complications of shortness of breath, arrhythmias, easy fatigability, chest pain, thromboembolic manifestations or congestive gastroentropathy symptoms and echocardiographic features of cardiomyopathy. The diagnosis of dilated cardiomyopathy (DCM) was essentially one of exclusion and was based on clinical symptoms, electrocardographic and chest roentgenographic findings of ventricular dysfunction, supported by echocardiographic or angiographic confirmation of global ventricular dilatation: left ventricular end diastolic volume more than or equal to $110 \mathrm{~cm}^{3} / \mathrm{m}^{2}$, left ventricular end systolic volume more than or equal to $44 \mathrm{~cm}^{3} / \mathrm{m}^{2}$, and left ventricular ejection fraction more than or equal to $50 \%$. The diagnosis of hypertrophic cardiomyopathy (HCM) was based on specific echocardiographic criteria [8]. Echocardiographic measurements for HCM included left ventricular septal wall thickness, typically $>15 \mathrm{~mm}$, dilated left atrium $(>4 \mathrm{~cm})$ and left ventricular enddiastolic diameter $<45 \mathrm{~mm}$. Normally, for the athletic heart, the septum is $<15 \mathrm{~mm}$, the left atrium is $<4 \mathrm{~cm}$ and left ventricular end-diastolic diameter $>45 \mathrm{~mm}$.

Restrictive cardiomyopathy (RCM), in which endomyocardial scarring may affect one or both ventricles restricting ventricular filling was based on echocardiographic findings, and/or the hemodynamic changes during ventriculography are diagnostic [9]. Peripartum cardiomyopathy was defined as $\mathrm{CHF}$ that occurs late in pregnancy or during the early postpartum period (the last trimester or up to 3 months postpartum) in the absence of congenital, coronary, or valvular heart disease or another recognized cause of heart failure. Patients were described to have unclassified cardiomyopathy when they did not fit readily into any group defined above.

Diagnosis of isolated ventricular noncompaction was based on the strict criteria of echocardiography. The criteria were an absence of significant heart lesions; segmental thickening of the left ventricular myocardial wall consisting of two layers consisting of a thin, compacted epicardial and an extremely thickened endocardial layer with prominent trabeculations and deep recesses [10].

We reviewed the clinical data of patients hospitalized with cardiomyopathy which included sociodemographic characteristics, symptoms, smoking habits, history of maternal gestational DM (DCM), medication, clinical examination, laboratory tests, chest X-ray, electrocardiogram, echocardiogram, stress test and/or cardiac catheterization (if available), as well as cardiac and/or skeletal biopsy (if needed).

Data are expressed as mean and standard deviation unless otherwise stated. Student's t test was used to ascertain the significance of differences between mean values of two continuous variables. Fisher exact test and $\chi^{2}$ tests were performed to test for differences in proportions of categorical variables between two or more groups. The level $\mathrm{p}<0.05$ was taken as the cut-off value for significance.

\section{Results}

During the 8-year study period, 132 patients were diagnosed with idiopathic cardiomyopathy. Of these, $31.8 \%$ were Qataris and $68.2 \%$ non-Qataris. Of the Qatari patients, 33.3\% married first degree relatives and $23.8 \%$ second degree relatives, giving a high level of consanguineous marriages.

The sociodemographic features and clinical characteristics of all types of cardiomyopathy by nationality during the study period are shown in table 1 . The proportion of males $(67.4 \%)$ was double that of females (32.6\%). A majority of the adult cases were above 35 years of age. On average, in children below 15 years of age, the incidence rate of all types of cardiomyopathies was $2.9 / 100,000$ population. For all types of cardiomy- 
Table 1. Sociodemographic features and clinical characteristics of all types of cardiomyopathy in Qatar by nationality

\begin{tabular}{|c|c|c|}
\hline Variables & $\begin{array}{l}\text { Qatari } \\
(n=42)\end{array}$ & $\begin{array}{l}\text { Non-Qatari } \\
(\mathrm{n}=90)\end{array}$ \\
\hline \multicolumn{3}{|l|}{ Gender } \\
\hline Male & $22(52.4)$ & $67(74.4)$ \\
\hline Female & $20(47.6)$ & $23(25.6)$ \\
\hline \multicolumn{3}{|l|}{ Age group } \\
\hline$\leq 15$ years & $10(23.8)$ & $25(27.8)$ \\
\hline $16-35$ years & $9(21.4)$ & $12(13.3)$ \\
\hline$>35$ years & $23(54.8)$ & $53(58.9)$ \\
\hline \multicolumn{3}{|l|}{ Body Mass Index } \\
\hline$<25$ (normal) & $14(34.1)$ & $42(53.2)$ \\
\hline$\geq 25$ (overweight) & $27(65.9)$ & $37(46.8)$ \\
\hline Smoking & $9(21.4)$ & $27(30.0)$ \\
\hline \multicolumn{3}{|l|}{ Cardiomyopathy } \\
\hline DCM & $30(71.4)$ & $70(77.8)$ \\
\hline $\mathrm{HCM}$ & $6(14.3)$ & $12(13.3)$ \\
\hline LVNC & $1(2.4)$ & $7(7.8)$ \\
\hline ARVC & $1(2.4)$ & $0(0.0)$ \\
\hline RVC & $1(2.4)$ & $0(0.0)$ \\
\hline Unclassified cardiomyopathy & $3(7.1)$ & $1(1.1)$ \\
\hline \multicolumn{3}{|l|}{ Associations } \\
\hline Diabetes mellitus & $12(28.6)$ & $3(3.3)$ \\
\hline Hypertension & $14(33.3)$ & $18(20.0)$ \\
\hline Ejection fraction & $38.4 \pm 15.9$ & $37.9 \pm 13.9$ \\
\hline \multicolumn{3}{|l|}{ Presentation } \\
\hline Shortness of breath & $25(59.5)$ & $51(56.7)$ \\
\hline Accidentally & $8(19.0)$ & $28(31.1)$ \\
\hline Palpitation & $12(28.6)$ & $12(13.3)$ \\
\hline Easy fatigue & $7(16.7)$ & $10(11.1)$ \\
\hline Chest pain & $5(11.9)$ & $15(16.7)$ \\
\hline Abdominal pain & $2(4.8)$ & $4(4.4)$ \\
\hline Stroke & $0(0.0)$ & $3(3.3)$ \\
\hline Deaths & $6(14.2)$ & $1(1.1)$ \\
\hline
\end{tabular}

DCM = Dilated cardiomyopathy; HCM = hypertrophic cardiomyopathy; LVNC = left ventricle noncompaction cardiomyopathy; ARVC = arrhythmogenic right ventricular cardiomyopathy; $\mathrm{RVC}=$ restrictive cardiomyopathy. Figures in parentheses indicate percentages. opathies, DCM rate was the highest (75.8\%), followed by HCM $(13.6 \%)$ and left ventricle noncompaction cardiomyopathy (6.1\%). RCM and ARVC (arrhythmogenic right ventricular cardiomyopathy) were the least $(0.8 \%)$. The most common presentations for cardiomyopathies were shortness of breath (57.6\%), palpitations (18.2\%), chest pain (15.2\%) and easy fatigability (12.9\%). Abdominal pain was the main symptom in $4.6 \%$ of the cases, while stroke was an early manifestation in $2.3 \%$ of cases. Twenty-seven percent of the patients were smokers.

All types of cardiomyopathies by age group are presented in table 2. DCM was the most prevalent cardiomyopathy in all age groups and the incidence increased remarkably with age. Hypertropic cardiomyopathy had two peaks; one below 15 years of age and the other in the $36-50$ years age group. Nearly half (48.6\%) of the children had DCM, 28.6\% HCM and 20\% left ventricular noncompaction cardiomyopathy.

From 1996 to 2002, the rate of all types of cardiomyopathies remained at 2.5/100,000 population per year (95\% CI: $1.4-3.5$ ), but it increased to $5.2 / 100,000$ population in 2003 (95\% CI: 3.6-6.7). Also, the prevalence rate of DCM was $17.5 / 100,000$ population, which was much higher than HCM (3.1/100,000 population). Prevalence rates were greater for men, with a male:female ratio of 2:1 for both DCM and HCM. The percentage of deaths due to cardiomyopathy was $5.3 \%$, and all these were in the 16-35 years age group (table 2). Four deaths occurred in cases with DCM and one in RCM. DCM due to thalassemia was associated with the shortest period between diagnosis and death (2 years).

A rare association between cardiomyopathies and certain diseases is shown in table 3. Among those cases, antiphospholipid syndrome and scleroderma have not been reported before.

Table 2. Type of cardiomyopathies by age group during the 1996-2003 period

\begin{tabular}{llllllll}
\hline Age group & DCM & HCM & LVNC & ARVC & RCM & UCM & Total \\
\hline $1-15$ years & 17 & 10 & 7 & 0 & 0 & 1 & 35 \\
$16-35$ years & 16 & 2 & 1 & 1 & 1 & 0 & 21 \\
$36-50$ years & 67 & 6 & 0 & 0 & 0 & 3 & 76 \\
Total (\%) & $100(75.8)$ & $18(13.6)$ & $8(6.1)$ & $1(0.8)$ & $1(0.5)$ & $4(3.0)$ & $132(100)$ \\
\hline
\end{tabular}


Table 3. A rare association between cardiomyopathies and certain diseases during the 1996-2003 period in Qatar

\begin{tabular}{|c|c|c|c|c|c|c|}
\hline Disease & $\begin{array}{l}\text { Type of } \\
\text { cardiomyopathy }\end{array}$ & $\begin{array}{l}\text { Age } \\
\text { years }\end{array}$ & Sex & $\mathrm{EF}$ & Comment & Incidence \\
\hline Antiphospholipid syndrome & DCM & 38 & $\mathrm{~m}$ & $21 \%$ & normal coronaries & $1(0.8 \%)$ \\
\hline \multirow[t]{2}{*}{ Familial conus dystrophy } & DCM & 19 & $\mathrm{~m}$ & $38 \%$ & completely normalized & \\
\hline & & & & & EF in 2 months & $1(0.8 \%)$ \\
\hline Ebstien disease & LV noncompaction & 1 & $\mathrm{f}$ & $50 \%$ & & $1(0.8 \%)$ \\
\hline Thyroid disorders & DCM & $43-47$ & $\mathrm{~m} / \mathrm{f}$ & $30-45 \%$ & & $3(2.2 \%)$ \\
\hline Myofibrillar myopathy & $\mathrm{RCM}$ & 16 & $\mathrm{~m}$ & $32 \%$ & died within 5 years & $1(0.8 \%)$ \\
\hline Thalassemia & DCM & $20-21$ & $\mathrm{~m}$ & $14-21 \%$ & died within 2 years & $2(1.5 \%)$ \\
\hline Scleroderma & DCM & 39 & $\mathrm{f}$ & $23 \%$ & ICD implanted & $1(0.8 \%)$ \\
\hline Acute myeloid leukemia & $\mathrm{HCM}$ & 10 & $\mathrm{f}$ & $77 \%$ & & $1(0.8 \%)$ \\
\hline
\end{tabular}

\section{Discussion}

There is no previous report describing the epidemiology of idiopathic cardiomyopathy in Qatar. In the 10-year period between 1991 and 2001, 2,342 patients were hospitalized with CHF. Of these, 53\% were Qatari with CHF and hypertension [1]. The high consanguinity rate (46\%) in Qatar made us register the incidence of idiopathic cardiomyopathy. We had previously reported striking patterns of cardiomyopathy in two Qatari families [1, 2, 4].

Depending on the diagnostic criteria, the reported annual incidence of idiopathic DCM varied between 5 and 8 cases per 100,000 population [4, 11-13]. In our study, the overall prevalence of all types of cardiomyopathy was $2.5 / 100,000$ population per year during the 1996-2002 period, and it doubled to $5.2 / 100,000$ population in the year 2003. This could be explained in part by our greater awareness of such issue and also because, for this year, it was a prospective study. During the study period between 1996 and 2003, the prevalence of DCM and HCM were 17.5 and 3.1 per 100,000 population, respectively. However, the true incidence is probably underestimated, since many asymptomatic cases remain undetected. The ageadjusted prevalence of idiopathic DCM in the United States averages to 36 cases per 100,000 population [14]. In Japan, a nationwide epidemiological survey to estimate the total number of patients with idiopathic cardiomyopathy and the prevalence of the disorder revealed that crude prevalence per 100,000 population was estimated to be 14.0 for DCM, 17.3 for HCM and 0.2 for RVM [15]. The true natural history of idiopathic DCM is difficult to determine, since asymptomatic cardiomegaly may be present for months or years before being de- tected. Survival data from tertiary referral centers are similar, with a mortality rate ranging between 25 and $30 \%$ in 1 year and approximately $50 \%$ in 5 years [16-18]. The overall mortality rate in our study was $5.3 \%$.

Most of the patients with cardiomyopathy are usually first seen between the ages of 20 and 50 years, but the disorder may also affect the children and the elderly [17, 18]. The most common initial manifestation is heart failure, which occurs in $75-85 \%$ of patients. In most cases initial symptoms include dyspnea on exertion (86\%), palpitations (30\%) and peripheral edema (29\%). Asymptomatic cardiomegaly is detected in $4-13 \%$ of patients. Abdominal pain is not an uncommon presentation either. Chest pain on exertion occurs as an initial symptom in $8-20 \%$ of patients [18-20], and eventually occurs in approximately $35 \%$. Systemic and pulmonary emboli are the initial manifestations in $1.5-4 \%$ of cases. Although atrial fibrillation is more common among patients with embolic events, it is present in fewer than $25 \%$ of such patients. Ventricular arrhythmias are common, but syncope and sudden death are rarely the initial presentation of the condition [15-18]. In our study, the more frequent symptoms of cardiomyopathy were SOB (57.6\%), palpitation $(18.2 \%)$, chest pain $(15.2 \%)$ and easy fatigue $(12.9 \%)$.

Ideally, all patients with DCM should be shown to be free of coronary artery disease (CAD); however, in practice, coronary angiography is not routinely performed in all cases with CHF. Thus, retrospective studies cannot control the conditions under which patients are recruited or investigated. It follows that most epidemiologic studies of DCM have compromised on the completeness of data on $\mathrm{CAD}$ in their subjects. In an Icelandic study, $75 \%$ of 
Table 4. Reported studies for idiopathic cardiomyopathy

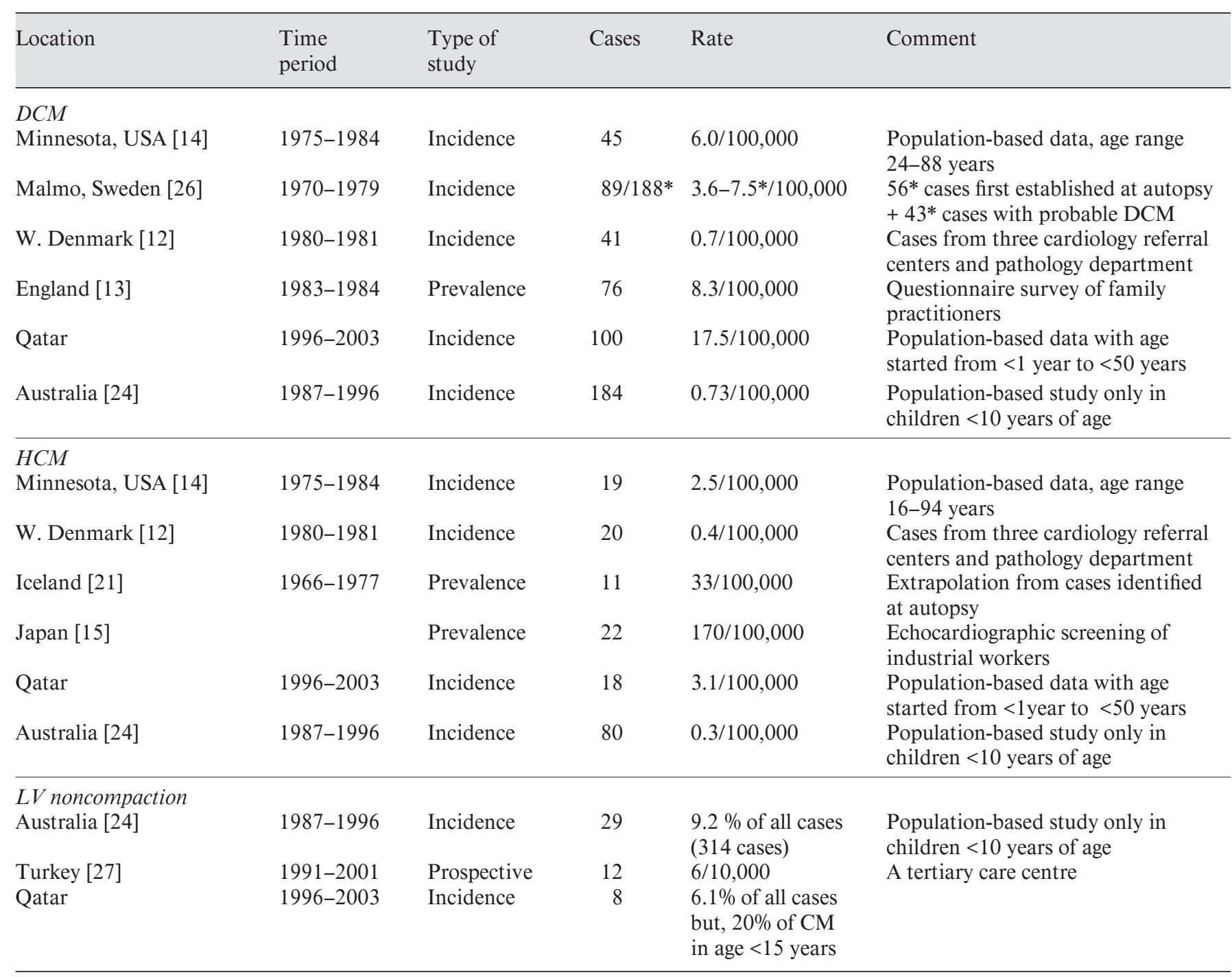

patients were shown to have normal coronary circulation [21]. In studies at Mayo Clinic, the incidence of normal coronary circulation for DCM was 58 and 47\%, respectively [14]. In our study, we excluded cardiomyopathies complicating myocardial infarction, and only 7 cases were documented to have CAD, confirmed by angiography.

The true incidence of pediatric cardiomyopathy is also unclear. In comparison with the annual incidence of cardiomyopathy in children in a North American $(1.3 / 100,000)$, a Finnish $(0.74 / 100,000)$ and an Australian study $(1.24 / 100,000)$ [21-26], our study showed a higher rate $(2.6 / 100,000)$ for the 8 -year period. This higher incidence in our study might be related to the high consanguinity rate in Qatar (46\%). Left ventricle non- compaction cardiomyopathy constituted $6.1 \%$ of all cardiomyopathies and $20 \%$ of pediatric and $0.97 \%$ of adult cardiomyopathies in Qatar. Worldwide, the incidence of left ventricular noncompaction cardiomyopathy is 0.05 $0.24 \%$ in adults $[25,27]$. Table 4 summarizes some of the reported studies for cardiomyopathy.

\section{Study Limitations}

The retrospective part of the study has some limitations. Coronary angiography was not available for a majority of the cases. The diagnosis of RCM was based only on echocardiographic findings. However, cardiac catheterization is essential to confirm the diagnosis of RCM. Genetic analysis was not performed. 


\section{Conclusion}

This study revealed that the incidence of idiopathic cardiomyopathy was high in children below 15 years and in adults above 35 years. Introducing preventive and early diagnostic programs may have an impact on reducing the mortality and morbidity rates of idiopathic cardiomyopathy. Routine baseline echocardiographic study and genetic analysis are recommended in families with consanguineous marriages and a history of idiopathic cardiomyopathy.

\section{References}

-1 Bener A, Al Suwaidi J, El-Menyar A, Gehani AA: The effect of hypertension as a predictor of risk for congestive heart failure patients over a 10-year period: a cross-cultural comparison. Blood Pressure 2004;13:41-46.

-2 El Menyar A, Al Suwaidi J, Gehani AA, Bener A: Clinical and histological studies in Qatari family with myofibrillar myopathy. Case report. Saudi Med J 2004,25:1723-1726.

-3 Selcen D, Ohno K, Engel G: Myofibrillar myopathy: clinical, morphological and genetic studies in 63 patients. Brain 2004,127:439451.

-4 El Menyar AA, Bener A, Al Suwaidi J: Cardiovascular manifestations of myofibrillar myopathy. Anadolu Kardiyol Derg 2004,4:336338 .

5 Bener A, AlAli KA: Consanguineous marriages in a newly developed country: Qatari population. J Biosoc Sci 2004:1-8. DOI: 10.1017/S0021932004007060.

-6 World Health Organization: Report of the WHO/ISFC task force on the definition and classification of cardiomyopathies. Br Heart J 1980;44:672.

77 Richardson, P: Report of the 1995 World Health Organization/International Society and Federation of Cardiology Task Force on the Definition and Classification of the Cardiomyopathies. Circulation 1996;93:841.

-8 Shapiro LM, Mckenna WJ: Distribution of left ventricular hypertrophy in HCM: a two-dimensional echocardiography study. J Am Coll Cardiol 1983;2:437-444.

-9 Ammash N, Seward J, Bailey K, Edwards WD, Tajik AJ: Clinical profile and outcome of idiopathic restrictive cardiomyopathy. Circulation 2000; 101:2490.

10 Oechslin EN, Jost CH, Rojas JR, Kaufmann PA, Jenni R: Long-term follow-up of 34 adults with isolated left ventricular noncompaction: a distinct cardiomyopathy with poor prognosis. J Am Coll Cardiol 2000;36:493-500.
11 Gillum RF: Idiopathic cardiomyopathy in the United States, 1970-1982. Am Heart J 1986; 111:752-755.

12 Bagger JP, Baandrup U, Rasmussen K, Moller $\mathrm{M}$, Vesterlund T: Cardiomyopathy in western Denmark. Br Heart J 1984;52:327-331.

13 Williams DG, Olsen EGJ: Prevalence of overt dilated cardiomyopathy in two regions of England. Br Heart J 1985;54:153-155.

14 Codd MB, Sugrue DD, Gersh BJ, Melton LJ III: Epidemiology of idiopathic dilated and hypertrophic cardiomyopathy: a populationbased study in Olmsted Country, Minnesota 1975-1984. Circulation 1989;80:564-572.

15 Miura K, Nakagawa H, Morikawa Y, Sasayama S, Matsumori A, Hasegawa K, Ohno Y, Tamakoshi A, Kawamura T, Inaba Y: Epidemiology of idiopathic cardiomyopathy in Japan: results from a nationwide survey. Heart 2002,87:126-130.

-16 Sugrue DD, Rodeheffer RJ, Codd MB, Ballard DJ, Fuster V, Gersh BJ: The clinical course of idiopathic dilated cardiomyopathy: a population-based study. Ann Intern Med 1992;117: 117-123.

17 Diaz RA, Obasohan A, Oakley CM: Prediction of outcome in dilated cardiomyopathy. B Heart J 1987;58:393-399.

18 Di Lenarda A, Lardieri G, Mestroni L, Miani D, Pinamonti B, Salvi A, Singuara G, Camerini F: Dilated cardiomyopathy: changing survival in the last 20 years. Circulation 1990; 82:(suppl 3):387, abstract No 1536.

19 Stevenson LW, Perloff JK: The dilated cardiomyopathies: clinical aspects. Cardiol Clin 1988;6:187-218
20 Boucek MM, Faro A, Novick RJ, Bennett LE, Keck BM, Hosenpud JD: The Registry of the International Society of Heart and Lung Transplantation: Fourth Official Pediatric Report 2000. J Heart Lung Transplant 2001;20:39_ 52.

21 Bjarnason I, Jonsson S, Hardarson T: Mode of inheritance of hypertrophic cardiomyopathy in Iceland: echocardiographic study. Br Heart J 1982;47:122-129

22 Arola A, Jokinen E, Ruuskanen O, Saraste M, Pesonen E, Kuusela AL, Tikanoja T, Paavilainen T, Simell O: Epidemiology of idiopathic cardiomyopathies in children and adolescents: a nationwide study in Finland. Am J Epidemiol 1997; 146:385-393.

23 Arola A, Tuominen J, Ruuskanen O, Jokinen $\mathrm{E}$ : Idiopathic dilated cardiomyopathy in children: prognostic indicators and outcome. Pediatrics 1998;101:369-376.

24 Nugent AW, Daubeney PEF, Chondros P, Carlin JB, Cheung M, Wilkinson LC, Davis AM, Kahler SG, Chow CW, Wilkinson JL, Weintraub RG: The epidemiology of childhood cardiomyopathy in Australia. N Engl J Med 2003; 348:1639-1646.

25 Ritter M, Oechslin E, Sütsch G, Attenhofer C, Schneider J, Jenni R: Isolated noncompaction of the myocardium in adults. Mayo Clin Proc 1997; 72:26-31.

26 Torp A: Incidence of congestive cardiomyopathy; in Goodwin JF, Hjalmarson A, Olsen EGJ (eds): Congestive Cardiomyopathy: Proceedings of a Symposium Held in Kiruna, Sweden, 1980. Moelndal, AB Haessle, 1981, pp 1822.

-27 Ozkutlu S, Ayabakan C, Celiker A, Elshershari $\mathrm{H}$ : Noncompaction of ventricular myocardium: a study of twelve patients. J Am Soc Echocardiogr 2002; 15:1523-1528. 